\title{
Central diabetic insipidus associated with suspected pituitary gland tumor in a dog
}

\author{
Kyo-Im Lee, Hee-Myung Park* \\ BK21 Basic \& Diagnostic Veterinary Specialist Program for Animal Diseases and \\ Department of Veterinary Internal Medicine, College of Veterinary Medicine, Konkuk University, Seoul 143-701, Korea
}

(Received: August 30, 2011; Revised: November 29, 2011; Accepted: November 30, 2011)

\begin{abstract}
A 12-year-old spayed female Yorkshire terrier dog was presented with two-weeks history of lethargy, mental dullness and polydipsia. Neurologic examination revealed proprioceptive defect of all limbs and loss of swallowing gag reflex. The dog revealed persistent dehydration, hypernatremia, hyperosmolarity and hyposthenuria. On magnetic resornance imaging (MRI), the mass were heterogeneous signality on $\mathrm{T} 1$ weighted images, hyperintense signality on $\mathrm{T} 2$ weighted image with contrast enhancement on hypothalamohypophyseal lesion. Based on these findings, the dog was suspected as having pituitary gland tumor. Through water deprivation test and response to desmopressin acetate (1-deamino-8-Darginine, DDAVP), this case was diagnosed by central diabetes insipidus (CDI). This paper reports the clinical sign, MRI, response to the exogenous antidiuretic hormone of CDI due to suspected pituitary tumor in a dog and DDAVP administration was evaluated effective therapy to correct hypernatremia induced by CDI.
\end{abstract}

Key words : central diabetes insipidus, DDAVP, dog, pituitary tumor

\section{Introduction}

Diabetes insipidus (DI) is characterized by polyuric and polydipsic disorder with inadequate urine concentration ability results from insufficient antidiuretic hormone (ADH) secretion or action [7]. Central diabetes insipidus (CDI) results from a deficiency of arginine vasopressin caused by destruction of the paraventricular and supraoptic nuclei of the hypothalamus or loss of the major ducts that transport arginine vasopressin to the posterior lobe of the pituitary gland [7, 13, 29]. Nephrogenic diabetes insipidus results from the reduced capacity of $\mathrm{ADH}$ to bind to its renal receptor and exert influence on its renal action $[4,7]$.

Vasopressin is a peptide secreted by the neurohypophysis in response to small increase plasma osmolarity [29]. Acting on vasopressin $\left(\mathrm{V}_{2}\right)$ receptor in renal collecting duct, vasopressin leads to water reabsorption and excretion of concentrated urine, maintaining eunatremia $[15,29]$. Lack of vasopressin production and secretion, which is commonly observed clinicopathologic disorder associated with pituitary gland lesion, including tumor, trauma and congenital defect, can lead to CDI $[3,10,13,18,23,24]$. It causes the loss of free water through the kidneys and can lead to severe polyuria, hyposthenuria, and hyponatremia [9]. Establishing a diagnosis of CDI is based on exclusion of other causes of polyuria and polydipsia (PU/PD), results of modified water deprivation test, response to treatment with exogenous ADH and/or confirmation of hypothalamohypophyseal lesion on advanced diagnostic brain imaging technique $[9,10,13,24]$.

The present case describes the clinical signs, magnetic resonance imaging (MRI), response to the exogenous $\mathrm{ADH}$ of $\mathrm{CDI}$ due to suspected pituitary tumor in a dog.

\section{Case Report}

A 12-year-old spayed female Yorkshire terrier dog was presented with two-weeks history of lethargy, mental dullness and polydipsia. On physical examination, decreased skin turgor, delayed capillary refill time,

\footnotetext{
*Corresponding author

Tel: +82-2-450-4140, Fax: +82-2-450-3037

E-mail: parkhee@konkuk.ac.kr
} 
systemic hypotension (systolic blood pressure: 109 $\mathrm{mmHg}$, reference range: $120 \sim 140 \mathrm{mmHg}$ ) and sinus bradycardia ( 66 beats per min) were observed. Neurologic examination revealed proprioceptive defect of all limbs and loss of swallowing gag reflex. Other cranial nerve reflex and spinal reflex was normal. There were no specific findings on complete blood counts and serum chemistry profiles except electrolyte values. Hypernatremia ( $160 \mathrm{mmol} / \mathrm{L}$, reference range, $140 \sim 150 \mathrm{mmol} / \mathrm{L}$ ) and serum hyperosmolarity $(338 \mathrm{mOsm} / \mathrm{kg}$, reference range, 290 301 mmol/L) were revealed. Urinalysis revealed isosthenuria (urine specific gravity, USG: 1.014). Because of hypernatremia was presumed resulting to dehydration, fluid therapy was administered consisted of normal saline. Thoracic and abdominal radiographs revealed spondylosis deformans at fourth and fifth lumbar region, but no other abnormalities. On day 2, serum sodium concentrations had decreased but were not in the normal range $(155 \mathrm{mmol} / \mathrm{L}$, reference range, $140 \sim 150 \mathrm{mmol} / \mathrm{L}$ ). Fluid treatment was changed to $0.45 \% \mathrm{NaCl}$ and spironolactone (Spiracton; Daewon, Korea; $2 \mathrm{mg} / \mathrm{kg}$, PO, BID) was administered to correct hypernatremia. Because of adrenocorticotrophic hormone stimulation test demonstrated a normal concentration of cortisol and low concentration of aldosterone (pre: 11, reference: $14 \sim 957 \mathrm{pg} / \mathrm{mL}$, post: 40.5 , reference: 197 $2,103 \mathrm{pg} / \mathrm{mL}$ ), hyperadrenocorticism was ruled out. On day 3, serum sodium concentration was normal (149 $\mathrm{mmol} / \mathrm{L}$ ) with isothenuria (SG: 1.010). However the dog revealed anisocoria with delayed papillary light reflex (PLR) and decreased gag reflex response and tongue movement suddenly. Therefore, increasing of intracranial pressure (ICP) was suspected, the dog was treated with prednisolone (Solondo; Yuhan Medica, Korea; $1 \mathrm{mg} / \mathrm{kg}$, PO, BID) and mannitol (D-mannitol daihan Inj; Daihan, Korea; $1 \mathrm{~g} / \mathrm{kg}$, IV, TID). Fluid therapy was changed to $0.9 \% \mathrm{NaCl}$. Atropine response test was performed because of sinus bradycardia (49 bpm) was persisted. Through atropine response test, comparing to pre and post electrocardiography (ECG), sick sinus syndrome (SSS) was ruled out. On day 5, the dog was more alert and responsive after decompression of ICP. The dog had normal gag reflex with tongue movement, however anisocoria was persisted with mildly improved PLR. Because of intracranial lesion was suspected, MRI was performed using a 0.2 Tesla MRI (Vet-MR; Esaote, Italy). An ovoid mass $(1.5 \mathrm{~cm}$ in height $)$ at the diencephalon was visible associated compression of the

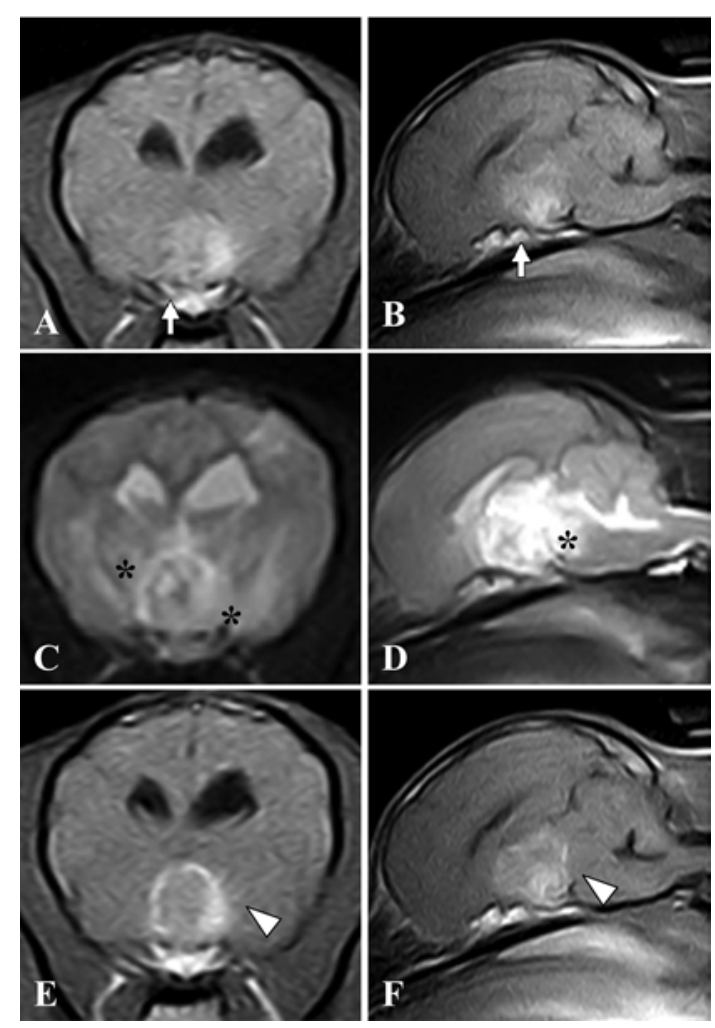

Fig. 1. MRI in this dog with central diabetes insipidus associated with suspected pituitary gland tumor. (A) Transverse and (B) mid-sagittal T1 weighted imaging at the level of interthalamic adhension. An ovoid mass $(1.5 \mathrm{~cm}$ in height, arrow) at the interthalamic adhension is visible suspected pituitary origin. The mass was hyperintense and heterogeneous on T1 weighted images. (C) Transverse and (D) mid-sagittal T2 weighted MR imaging show hyperintense with a homogeneous pattern. Hyperintense signal area (asterisk) surrounds the mass represented cerebral edema. (E) Transverse and (F) mid-sagittal post-contrast MR imaging show a strongly ring-enhancing lesion (arrowhead). The mass at the diencephalon compresses of the interventricular area.

interventricular area. The mass was heterogeneously hyperintense on $\mathrm{T} 1$ weighted images and hyperintense with a homogeneous pattern on T2 weighted image (Fig. $1 \mathrm{~A}, \mathrm{~B}, \mathrm{C}$ and D). Hyperintense signal area surrounding the mass represented cerebral edema on the $\mathrm{T} 2$-weighted image (Figs. 1C and D). On the postcontrast T1 weighted image, a strongly ring-enhancing lesion was present (Figs. 1E and F). This finding was presumed with pituitary tumor. Collection of cerebrospinal fluid was not performed, because of concern about increased ICP. Treatments for brain lesion consisted of 
prednisolone (Solondo; $1 \mathrm{mg} / \mathrm{kg}, \mathrm{PO}, \mathrm{BID})$ and cyclosporine (Sandimmun neural; Novartis, Korea; $8 \mathrm{mg} / \mathrm{kg}$, PO, SID). After therapies for three days, the dog revealed clinical improvement with normal gag reflex. However hypernatremia $(158 \mathrm{mmol} / \mathrm{L}$ on day 8 and $178 \mathrm{mmol} / \mathrm{L}$ on day 9) and polyuria persisted with dehydration despite of aggressive fluid therapy. Because the dog was presumed as CDI due to hypothalamohypophyseal lesion, modified water deprivation tests were performed as previously described [8, 17]. The tentative diagnosis was regarded to DI, because of the USG did not increased (SG: 1.007) despite of 5\% dehydration. For final diagnosis of CDI, exogenous ADH, 1-deamino-8-D-arginine (DDAVP, Minirin; Ferring, Switzerland; $1 \mu \mathrm{g} / \mathrm{kg}, \mathrm{SC}$ ), was administered. Administration of DDAVP resulted in an increased USG, decreased serum sodium level and osmolarity. The USG increased from 1.007 to 1.020 over $9 \mathrm{~h}$. The plasma osmolarity and sodium level were, respectively, 370 $\mathrm{mOsm} / \mathrm{kg}$ and $178 \mathrm{mmol} / \mathrm{L}$ prior to DDAVP administration and $321 \mathrm{mOsm} / \mathrm{kg}$ and $151 \mathrm{mmol} / \mathrm{L} 9$ hours after administration. CDI was diagnosed ultimately by confirmation of serum and urine response after DDAVP administration and treatment was changed to maintain into sub-conjunctival (8 drop, in both eye) administration on day 11. After confirmation of serum osmolarity, sodium level and USG with urine osmolarity was maintained by sub-conjunctival DDAVP treatment, the dog was discharged. The dog was died about 1 week after out of hospitalization. Telephone contact with the owner indicated that the dog was not treated with subconjunctival DDAVP and comatose when she died. Necropsy was not performed.

\section{Discussion}

CDI is an endocrinopathy which is occurred from failure of the hypothalamohypophyseal system to effect of $\mathrm{ADH}$ to maintain normal body fluid homeostasis through renal free water conservation [13, 15, 29]. Differential diagnosis of PU/PD were primary dipsia, diabetes insipidus, renal disease, diabetes mellitus, liver disease, hypercalcemia and hyperadrenocorticism [25]. In this case, all other potential causes except primary polydipsia and diabetes insipidus were ruled out through physical examination, clinicopathologic findings and laboratory examination. Serum osmolarity is usually subnormal in the patient with primary polydipsia [25], however elevated in DI as this case. This reflects the different mechanisms of polyuric status. While primary polydipsia is induced by excessive water consumption, DI was induced by renal concentration defect [25]. The high value of serum osmolarity in this case gave diagnostic support for DI rather than primary polydipsia $[7,25]$. Modified water deprivation tests have been used to differentiate primary polydipsia and DI [7, 28]. Osmotic stimulation due to water deprivation test is a very strong stimulus for vasopressin secretion in healthy dogs [28]. However, USG is unable to excess of 1.008 $(<300 \mathrm{mOsm} / \mathrm{kg})$ in the dog with DI [13]. In previous reports, diagnosis of CDI was confirmed with results of modified water deprivation tests and response to treatment with exogenous antidiuretic hormone $[2,6,11$, 18]. For diagnosis of CDI, USG should increase to greater than 1.012 with a $50 \sim 500 \%$ increase in urine osmolarity after exogenous ADH administration $[8,17]$. In this case, urine of specific gravity 1.020 obtained 9 $\mathrm{h}$ after $\mathrm{ADH}$ administration leaded to final diagnosis of CDI.

The DDAVP, synthetic vasopressin analogue, has been the treatment for CDI in dogs and cats [2, 9, 13, 24]. DDAVP used to exhibit an antidiuretic effect for eight hours, which is relatively long, and strong effect to $V_{2}$ receptor, about three-four fold higher than that of arginine vasopressin [12]. Because of this selective character of DDAVP for $\mathrm{V}_{2}$ receptor, it is used for the treatment of CDI and associated with a low incidence of adverse effects [12, 14, 19]. In this dog, DDAVP had long duration of action, more than $20 \mathrm{~h}$ in subcutaneous injection and the response of osmolarities of serum and urine after DDAVP treatment was excellent. No clinical features suggesting water intoxication, such as subcutaneous edema, were observed during the period of DDAVP administration and the complications related to administration of DDAVP did not develop in this dog as previous report $[12,19]$. Almost cases of CDI had been well to treat DDAVP, however long term prognosis is variable depending on the underlying causes $[2,10$, 13]. The dogs with neurologic signs, which had a mass in the region of the pituitary gland, revealed short term follow-up compare to benign etiology (e.g., congenital, idiopathic) in a previous case [13]. This dog was died about 1 week after out of hospitalization. The cause of death was presumed hypernatremia by inappropriate medication and could not performed evaluation of long term prognosis. 
This dog revealed persistent sinus bradycardia. Causes of sinus bradycardia in dogs includes SSS, hypothyroidism, hypothermia, organophosphate toxicosis, pharmacologic cause, upper respiratory obstruction, cushing reflex and neurologic lesion [5]. SSS was ruled out through ECG response to atropine. Cushing reflex is that, increasing in mean arterial pressure triggers pressure receptors in aortic arch and carotid body, causing the heart rate to slow (baroreceptor reflex) [1, 30]. Because of the dog was normal blood pressure, cushing reflex was ruled out. Brain-heart syndrome has been described with intracranial pathologic lesions, that result from an imbalance in sympathetic stimulation to the heart, and ventricular premature contractions are seen most commonly [20, 26, 27]. Because of ECG finding in this dog, brain-heart syndrome was ruled out. Panhypopituitarism, defined as a complete failure of the pituitary to produce significant concentration of any hormone, was described concurrence in previous reports of CDI [3, 16, 18, 21, 24]. In this case, panhypopituitarism like as concurrent hypothyroidism was suspected, however thyroid panel was not performed. All other potential causes for bradycardia were ruled out through history, physical examination and clinicopathologic findings.

In this case, necropsy was not performed, however distinct lesion of hypothalamohypophyseal lesion revealed on MRI. Reported etiologies for CDI in dogs include primary and metastatic neoplasias, trauma, congenital defect, and idiopathic [9, 10, 13, 24]. The dog had no history of trauma and specific findings on diagnostic imaging associated with neoplasias in abdomen and thorax. Because MRI findings of this case were similar to pituitary tumor in previous reports of dogs and cats, the lesion was suspected as a primary tumor originated from pituitary gland [13, 22]. The singular mass, had well defined margin, compressed of the surrounding parenchyma and interventricular area. Especially, pituitary macroadenoma are large size (more than $1 \mathrm{~cm}$ ) and well defined ovoid with strong contrast enhancement at hypophyseal fossa similar to this dog $[13,22]$. In previous report, 6 of 20 dogs with CDI revealed neoplasia in the pituitary gland including craniopharyngioma, meningioma, chromophobe adenoma and adenocarcinoma [13]. In other report, one dog with CDI was diagnosed craniopharyngioma involving the thalamus, hypothalamus and pituitary gland [18]. There were diversity of tumor originated from pituitary gland in previous report, and this case was strongly suspected pituitary gland tumor on MRI. However, the investigation of tumor and its classification was not confirmed because of brain biopsy was not performed, and this is limitation of this report.

\section{Conclusion}

This case report was first describes CDI in our country. This case also demonstrates that CDI could be well controlled with DDAVP in a dog.

\section{Acknowledgments}

This study was supported by the Brain Korea 21 .

\section{References}

1. Abelson AL, Faissler D, Karas AZ. Anesthesia case of the month. Development of the Cushing reflex secondary to a dangerous increase in intracranial pressure. J Am Vet Med Assoc 2008, 232, 1298-1300.

2. Aroch I, Mazaki-Tovi M, Shemesh O, Sarfaty H, Segev G. Central diabetes insipidus in five cats: clinical presentation, diagnosis and oral desmopressin therapy. J Feline Med Surg 2005, 7, 333-339.

3. Authement JM, Boudrieau RJ, Kaplan PM. Transient, traumatically induced, central diabetes insipidus in a dog. J Am Vet Med Assoc 1989, 194, 683-685.

4. Cohen M, Post GS. Nephrogenic diabetes insipidus in a dog with intestinal leiomyosarcoma. J Am Vet Med Assoc 1999, 215, 1818-1820.

5. Côté E. Clinical Veterinary Advisor: Dog and Cat. 1st ed. pp. 1342, Mosby, St. Louis, 2007.

6. Court MH, Watson AD. Idiopathic neurogenic diabetes insipidus in a cat. Aust Vet J 1983, 60, 245247.

7. DiBartola SP. Renal disease: clinical approach and laboratory evaluation. In: Ettinger SJ, Feldman EC (eds.). Textbook of Veterinary Internal Medicine. 6th ed. pp. 1716-1722, Elsevier, St. Louis, 2005.

8. Feldman EC, Nelson RW. Canine and Feline Endocrinology and Reproduction. 3rd ed. pp. 2-44, Saunders, St. Louis, 2004.

9. Foley C, Bracker K, Drellich S. Hypothalamicpituitary axis deficiency following traumatic brain 
injury in a dog. J Vet Emerg Crit Care (San Antonio) 2009, 19, 269-274.

10. Ferguson DC, Biery DN. Diabetes insipidus and hyperadrenocorticism associated with high plasma adrenocorticotropin concentration and a hypothalamic/ pituitary mass in a dog. J Am Vet Med Assoc 1988, 193, 835-839.

11. Green RA, Farrow CS. Diabetes insipidus in a cat. J Am Vet Med Assoc 1974, 164, 524-526.

12. Hara Y, Masuda H, Taoda T, Hasegawa D, Fujita Y, Nezu Y, Tagawa M. Prophylactic efficacy of desmopressin acetate for diabetes insipidus after hypophysectomy in the dog. J Vet Med Sci 2003, 65, 17-22.

13. Harb MF, Nelson RW, Feldman EC, ScottMoncrieff JC, Griffey SM. Central diabetes insipidus in dogs: 20 cases (1986-1995). J Am Vet Med Assoc 1996, 209, 1884-1888.

14. Lam KS, Wat MS, Choi KL, Ip TP, Pang RW, Kumana CR. Pharmacokinetics, pharmacodynamics, long-term efficacy and safety of oral 1-deamino-8-Darginine vasopressin in adult patients with central diabetes insipidus. Br J Clin Pharmacol 1996, 42, 379 385 .

15. Mavrakis AN, Tritos NA. Diabetes insipidus with deficient thirst: report of a patient and review of the literature. Am J Kidney Dis 2008, 51, 851-859.

16. Mellanby RJ, Jeffery ND, Gopal MS, Herrtage ME. Secondary hypothyroidism following head trauma in a cat. J Feline Med Surg 2005, 7, 135-139.

17. Mulnix JA, Rijnberk A, Hendriks HJ. Evaluation of a modified water-deprivation test for diagnosis of polyuric disorders in dogs. J Am Vet Med Assoc 1976, 169, 1327-1330.

18. Neer TM, Reavis DU. Craniopharyngioma and associated central diabetes insipidus and hypothyroidism in a dog. J Am Vet Med Assoc 1983, 182, 519-520.

19. Nichols R, Hohenhaus AE. Use of the vasopressin analogue desmopressin for polyuria and bleeding disorders. J Am Vet Med Assoc 1994, 205, 168-173.

20. Ozdemir O, Hachinski V. Brain lateralization and sudden death: its role in the neurogenic heart syndrome.
J Neurol Sci 2008, 268, 6-11.

21. Platt SR, Chrisman CL, Graham J, Clemmons RM. Secondary hypoadrenocorticism associated with craniocerebral trauma in a dog. J Am Anim Hosp Assoc 1999, 35, 117-122.

22. Pollard RE, Reilly CM, Uerling MR, Wood FD, Feldman EC. Cross-sectional imaging characteristics of pituitary adenomas, invasive adenomas and adenocarcinomas in dogs: 33 cases (1988-2006). J Vet Intern Med 2010, 24, 160-165.

23. Post K, McNeill JR, Clark EG, Dignean MA, Olynyk GP. Congenital central diabetes insipidus in two sibling Afghan hound pups. J Am Vet Med Assoc 1989, 194, 1086-1088.

24. Ramsey IK, Dennis R, Herrtage ME. Concurrent central diabetes insipidus and panhypopituitarism in a German shepherd dog. J Small Anim Pract 1999, 40, 271-274.

25. Rijnberk A. Diabetes insipidus. In: Ettinger SJ, Feldman EC (eds.). Textbook of Veterinary Internal Medicine. 6th ed. pp. 1504-1505, Elsevier, St. Louis, 2005.

26. Thayer JF, Lane RD. Claude Bernard and the heartbrain connection: further elaboration of a model of neurovisceral integration. Neurosci Biobehav Rev 2009, 33, 81-88.

27. Thomason JD, Kraus MS, Surdyk KK, Fallaw T, Calvert CA. Bradycardia-associated syncope in 7 Boxers with ventricular tachycardia (2002-2005). J Vet Intern Med 2008, 22, 931-936.

28. van Vonderen IK, Wolfswinkel J, OosterlakenDijksterhuis MA, Rijnberk A, Kooistra HS. Pulsatile secretion pattern of vasopressin under basal conditions, after water deprivation, and during osmotic stimulation in dogs. Domest Anim Endocrinol 2004, 27, 1-12.

29. Vincent JL, Su F. Physiology and pathophysiology of the vasopressinergic system. Best Pract Res Clin Anaesthesiol 2008, 22, 243-252.

30. Wan WH, Ang BT, Wang E. The Cushing Response: a case for a review of its role as a physiological reflex. J Clin Neurosci 2008, 15, 223-228. 